\title{
中国濒危动物物种信息系统 (CESIS)
}

\author{
解 炎 陈 焰 邹学英 王 迪 汪 松 \\ (中国科学院动物研究所, 北京 100080)
}

\section{1 前言}

中国濒危动物物种信息系统已在中国科学院动物研究所基本建立, 该信息系统作为 中国科学院 八五”重大项目“生物多样性信息系统的初步建立”的课题之一,已于 1996 年 3 月通过验收, 并得到了较好的评价。

该信息系统自 八五”项目结束后又得到很大的发展,目前已经录入了哺乳类 1241 、 鸟类 2441 、爬行类 255 、两栖类 273 、鱼类 519 种或亚种的县级和保护区水平的分布; 以及 哺乳类 160 种、乌类 284 种、鱼类 101 种、两栖爬行类 108 种,共 653 种濒危物种的最新濒 危信息,并拥有使用方便且界面友好的用户服务程序,能够为政府有关部门及科研、教学 单位的管理、研究人员了解我国脊椎动物的分布, 以及濒危物种的分布数量、濒危等级、致 危因素、保护现状、保护措施建议、驯养繁殖状况等方面的最新信息,为物种的保护、管理 和研究提供必要的依据。

\section{2 中国濒危动物物种信息系统的主要功能及使用流程简介}

\section{1 查询和修改物种的信息 (图 1)}

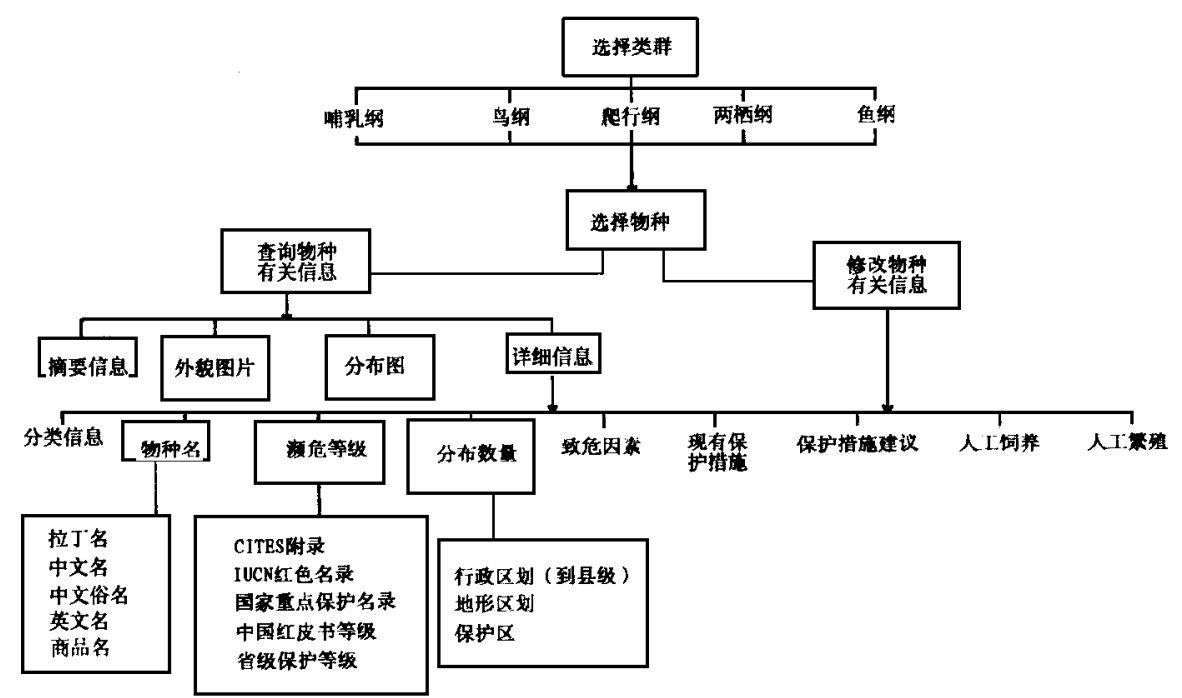

图 1 查询和修改物种信息

Fig. 1 Inquiring and editing information of a single species

* 致谢: 该系统作为科学院 八五”重大项目之一得到了中国科学院各级领导和主管部门的大力支持,在此表示衷心感谢! 自项目结束后,中国农业大学的杨玉剑、董辉、肖海红、曾利军 4 位同学以认真负责的态度录入了大量文献资料。中科院 动物所冯祚建研究员和罗桐女士为兽类标本卡片的录入、徐延恭研究员和何芬奇先生为鸟类标本卡片的录入工作提供了 支持和方便。林科院宋朝枢研究员和植物所钱迎倩研究员为保护物种的录入工作提供了许多资料,在此对他们表示诚挚 的谢意。 
通过本信息系统可以查询中国脊椎动物到县级和保护区的分布点名单,并可制作这些物 种在中国和各省的 GIS 图 (可打印彩色的物种分布 GIS 图)。对于中国的濒危脊椎动物, 除可 查询以上内容外，亦可查询到中国濒危动物种的信息概要、外貌图片;还可查询及修改脊椎动 物物种分类、名称、分布; 濒危脊椎动物的数量、现状、保护、驯养繁殖等方面详细的信息资料, 具体内容包括：

·分类信息:中国脊椎动物的纲、目、科、亚科、属、种、亚种的中文名和拉丁文名，定名人及 年代:

·名称 :中国脊椎动物的学名、中文种名、英文名、中文俗名、商品名;

-濒危等级:《濒危野生动植物种国际贸易公约》附录 (附录 I、附录 II、附录 III、未列入), 世 界自然保护联盟 (IUCN) 红色名录 (1994)（绝灭、濒危、易危、稀有、未定、资料不足、受威胁、贸 易致危、未列入)，国家重点保护野生动物名录 (一级、二级、未列入)，中国濒危野生动物红皮书 濒危等级 (野生绝迹、国内绝迹、濒危、渐危、稀有、未定、未列入)，省级保护等级 (一级、二级、列 入重点保护);

. 中国脊椎动物的地理分布和鸟的居留类型以及中国濒危脊椎动物的种群数量 : 按行政区 划必要时具体到县级的分布和数量, 必要时列出了地形区划 (山脉、河流、湖泊等)、全国自然保 护区的物种分布和数量, 并对各分布点有无标本记录作了注明;

.中国脊椎动物的致危因素:包括因食用、贸易、药用、与家养动物竞争食物及空间、作为有 害动物及其它原因而过度捕猎;栖息地破坏、洄游切断、环境污染、外来种的引入、种群隔离、种 内生物学特点、种内疾病、种间竞争、天敌动物等因素;

.中国脊椎动物的现有保护措施:包括地区保护等级、已建保护区、限制捕猎、限制贸易、特 殊保护组织、保护行动计划、繁殖谱系记录、人工饲养、人工繁殖及其它;

.中国脊椎动物的保护措施建议:包括开展生物学调研、就地保护、易地保护、保护行动计 划、保护措施及其它;

.中国脊椎动物的人工饲养状况;

.中国脊椎动物的人工繁殖状况。

2.2 各种类型的物种名录及选定物种的分布图 (图 2)

利用本信息系统, 可以从三个方面 (种群数量范围、物种类群、分布地区) 限制查询范围。 选定查询范围后, 该系统除能够列出选定范围内的所有物种 (即列出物种名录) 外, 还可以列出 选定范围内的许多其他的物种名录（包括属于某个濒危等级的物种名录; 具有某种致危因素或 者现有保护措施或者保护措施建议的物种名录; 以及有人工饲养和人工繁殖的物种名录等)。 并提供列出的物种在选定省份 (或全国) 的分布图。例如用户可以查询到某省的濒危哺乳类中 属于 IUCN 红色名录中濒危或易危的物种,并可通过分布图直观地了解这些物种在该省的分 布情况; 同样用户也能查询到某个保护区内由于作为医药成分而遭受捕猎的物种，从而为规划 或决策人员制订相应的保护措施提供科学依据。

该信息系统除能够列出各种物种名录外,还能够列出各个省份 (或全国) 的饲养单位和繁 殖单位的名录以及某个饲养或繁殖单位所饲养或繁殖的物种。

\section{3 参考文献查询}

本信息系统中的所有资料都注明了资料来源,并且用户可以通过输入完整或不完整的著 者名、文章名、书刊名、发表年代、出版社等查询到需要的资料目录。 


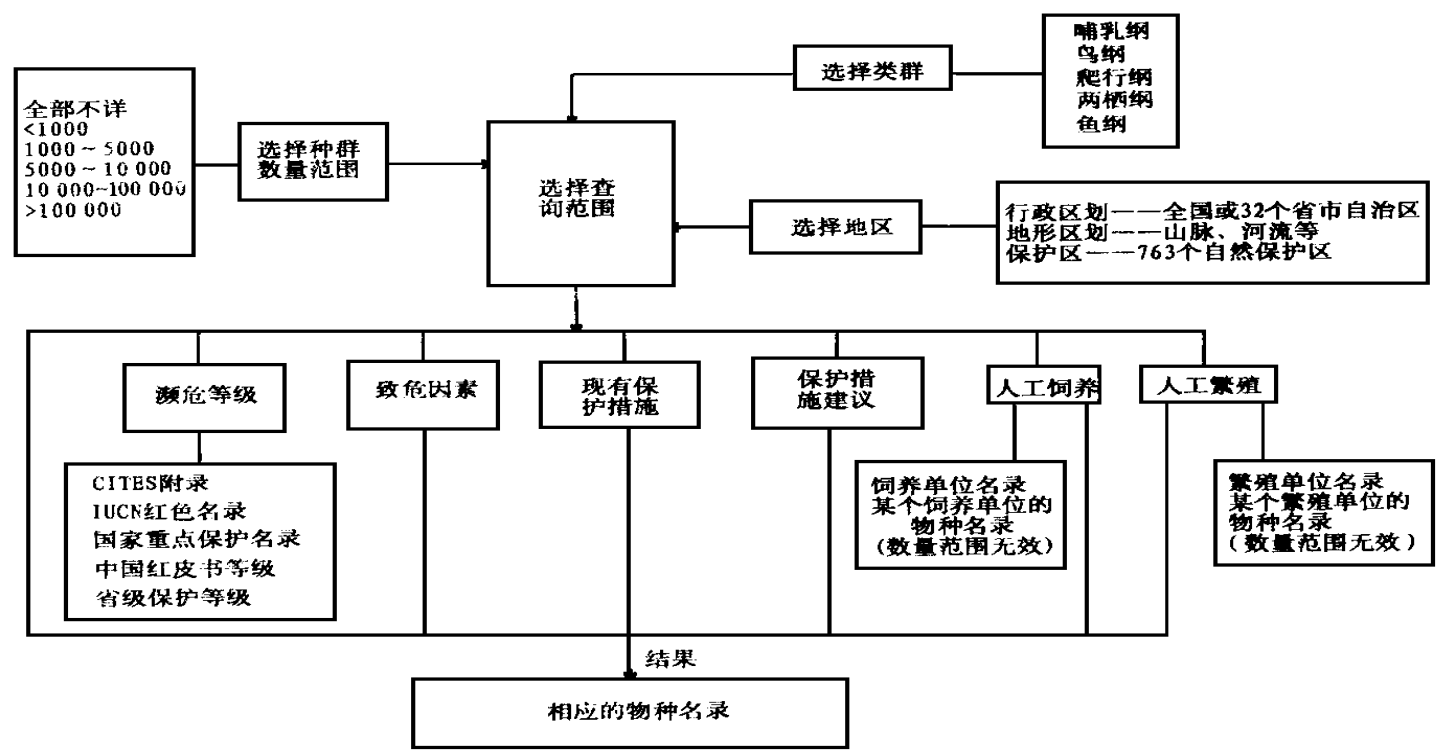

图 2 物种名录和分布图查询

Fig. 2 Inquiring species names and their distribution

3 需要继续开展的工作

3.1 数据信息系统是一项需要不断更新、充实的长期工作。数据库中的信息需要继续充实、 随时更新,特别是该信息系统刚刚建立，其中有的物种或者物种的某些方面的资料还很欠缺， 仍然需要大量的资料收集和录入工作,同时需要动物分类和生态学专家对现有的资料进行检 查，以便该系统能够提供准确的信息资料。在进一步完善该系统的信息资料后,我们将根据国 际濒危物种等级新标准的原则,科学地提出我国的红色名录。

3.2 加强本信息系统的统计分析功能,使本系统具有信息分析加工的能力, 能够直接为用户 提供多种分析结果，例如种群现状分析结果，物种间濒危状况、地区间濒危物种的比较结果等， 并提出适宜的物种保护的意见、建议,最大限度地为决策、保护和科研人员提供信息。

3.3 加强国际合作,更好地与国际接轨。该系统应考虑参与" 生物多样性保护信息系统” (Biodiversity Conservation Information System 或 BCIS)。使用国际统一代码, 与国际相关数据 库相连,并使之成为国际上涉及中国野生动物的濒危现状及保护信息最丰富、最全面、最新的 信息系统,从而在国际上占有一席之地。

3.4 加强国内合作, 与中国濒危植物数据库、中国物种数据库相联, 与这些数据库互通有无, 共同在国际、国内发挥更大的作用，为使用者特别是政府主管机构提供内容更广泛、信息更全 面的信息资料, 使数据库的作用得到尽量发挥, 成为我国及国际的有关中国物种多样性的主要 信息系统。

该信息系统的建立实为我国首次建立此类数据库,其意义远远超出本学科的范围,关系到 政策、法规、管理措施和行动计划的制订, 影响深远。由于我国濒危物种现状调查是个薄弱环 节, 按国际濒危物种等级新标准来估测, 我国高等动物濒危物种比例很大, 但已有资料十分欠 缺,因此极其需要各界人士的大力支持协助,向该信息系统提供可靠的数据资料和建议,共同 为中国的物种保护事业做一份贡献。 